\title{
A community engagement case study of The Somerville Mobile Farmers' Market
}

COMMENTARY ON RACE AND

ETHNICITY IN FOOD SYSTEMS

\author{
Erica Satin-Hernandez ${ }^{\text {* }}$ and Lisa Robinson b \\ Shape Up Somerville, Health and Human Services Department, \\ City of Somerville
}

Submitted June 15, 2015 / Published online August 21, 2015

Citation: Satin-Hernandez, E., \& Robinson, L. (2015). A community engagement case study of The Somerville Mobile Farmers' Market. Journal of Agriculture, Food Systems, and Community Development, 5(4), 95-98. http://dx.doi.org/10.5304/jafscd.2015.054.015

Copyright (C) 2015 by New Leaf Associates, Inc.

\begin{abstract}
The Somerville Mobile Farmers' Market, a food access initiative in Somerville, Massachusetts, is an example of community-municipality collaboration and a testament to the importance of community engagement, justice, and respect in the creation of a culturally relevant program. Traditional farmers' markets have been exclusive spaces catering to the white and elite, but through a community engagement process, The Somerville Mobile Farmers' Market has come to represent the immigrant-rich community in Somerville and increase food access in a culturally appropriate way.

a * Corresponding author: Erica Satin-Hermandez, Coordinator, Shape Up Somerville, Health and Human Services Department, City of Somerville; 50 Evergreen Avenue; Somerville, Massachusetts 02145 USA; +1-617-625-6600 x4321; eshernandez@somervillema.gov

${ }^{\mathrm{b}}$ Lisa Robinson, Director, Shape Up Somerville, Health and Human Services Department, City of Somerville; +1-617-6256600 x4312; 1robinson@somervillema.gov
\end{abstract}

\section{Keywords}

food access, food security, food system, farmers' market, mobile farmers' market, equity, community engagement, justice, health

Q hape Up Somerville (SUS) is a 15-year-old $\checkmark$ strategy in the Health and Human Services Department of the city of Somerville, Massachusetts which aims to build and sustain a healthier, more equitable community through policy, systems, and environmental change. Improving access to fresh food for low-income communities in Somerville is part of SUS's mission. In 2008, a supermarket in the immigrant-rich, lower-income neighborhood of Winter Hill closed, leaving residents with limited options for food access. In 2011, SUS and partner organizations Groundwork Somerville (a youth development and environmental justice organization) and The Welcome Project (an immigrant empowerment and service provision organization) facilitated a relationship 
with a local farm, Enterprise Farm, to create The Somerville Mobile Farmers' Market. While work takes place on other policy-based systemic approaches to the issue, this market provides a short- to midterm solution to food accessibility by selling fresh, local produce at low prices. Now in its fifth season, the evolution and success of this market is the product of a community-driven, culturally appropriate program supported by the unique collaboration between community and municipal entities. In our immigrant-rich community, this market defies the notion of farmers' markets as solely white and elite spaces. This commentary will reflect on how The Somerville Mobile Farmers' Market came into being and how we put the principles of community engagement, justice, and respect into action at the market.

The first step in preparation for any community collaboration is an awareness of skills and knowledge. Creating robust partnerships requires each player to understand the unique skills they bring to the table and respect the different skills of others. As actors in an institution-the municipality-SUS provides capacity in terms of infrastructural, financial, and staffing support, and must be aware of the community's expertise, crucial knowledge, and assets. To contribute to a robust partnership, we as a municipality must actively work against a siloed process that has historically excluded community groups, use a justice lens, and value sources of community knowledge, including those that are nontraditional. We can leverage our capacity to equitably collaborate with the community for deep change. To us, this requires long-term community engagement and respect for the community at all stages, from planning to implementation and evaluation, a value evident in our mobile farmers' market.

During the planning phase to address food access in Winter Hill, SUS worked with our nonprofit partners to host forums and discussions with community stakeholders about what type of food access initiative would be most helpful for their community. Some initial discussions at the SUS office had included a short-term solution of shuttle buses running from the city's easternmost housing development in Winter Hill (a half-mile and a sixlane highway away from the nearest grocery store) to other existing grocery stores. At one community forum, a youth community member taking part in a leadership development and language interpretation program from The Welcome Project suggested we follow the model common in her home country: carts with fresh produce for sale which visit multiple neighborhoods each day. Evidence from surveys done in Winter Hill that same year by the nonprofit Institute for Community Health also showed that residents desired a farmers' market for access to fresh, affordable produce. The idea of a traveling farmers' market-one borne of the community and less common in the U.S. currently-led to The Somerville Mobile Farmers' Market as an empowering, culturally relevant space. As SUS helps carry out the community's vision, it is important to properly recognize its origin. Whenever the history of the market is discussed, we believe it important to credit the community for the inception of the market model to give respect to the community that birthed this idea from their experience and knowledge.

Now that the market is established, community engagement, both directly and indirectly through our staff, helps increase our awareness of community assets and needs. Our primary employee, who started off as a cashier during the first year of the market and has moved up to market manager, is a resident of one of the city's housing developments (our primary locations) and is well connected in the community. The trust our customers have in her as a fellow community member is a crucial asset influencing the market's success as a communityserving and -building effort challenging the dominant narrative of farmers' markets as white, elite spaces. She receives candid feedback about the market that otherwise might not get relayed. For example, in the first year of the market her interactions with customers influenced our unique match program where we provide a 50 percent discount not only to people using SNAP, WIC, or Senior Farmers' Market Nutrition Program coupons but also to those who live in the housing developments but do not qualify for food assistance programs. Many farmers' markets offer a small matching program, but our market is unique in that roughly 75 percent of our customers use the match program, especially with our addition of 
housing development residents to the match program. In order to sustain our work, we now aggregate produce from multiple Massachusetts farms, buying wholesale up-front and then selling to our customers at lower-than-average retail prices (see Figures 1 and 2). With our low prices and match program, we must fundraise each year to support the produce cost and allow our farmers to receive the full cost of their produce but keep our prices low. A portion of all full-priced purchases goes to support the match program as well, bringing in a "social good" aspect for full-price shoppers and contributing to market sustainability. This setup allows us to offer affordable produce to all who want it, and we gather community input into our operations, from the guidelines of the match program to the types of produce we order each week. Awareness of our community's composition, issues, and strengths positively influences our

\section{Figure 1. The Somerville Mobile Farmers' Market van was provided by Massachusetts Department of Agricultural Resources grant and Herb Chambers Car Dealership sponsorship.}

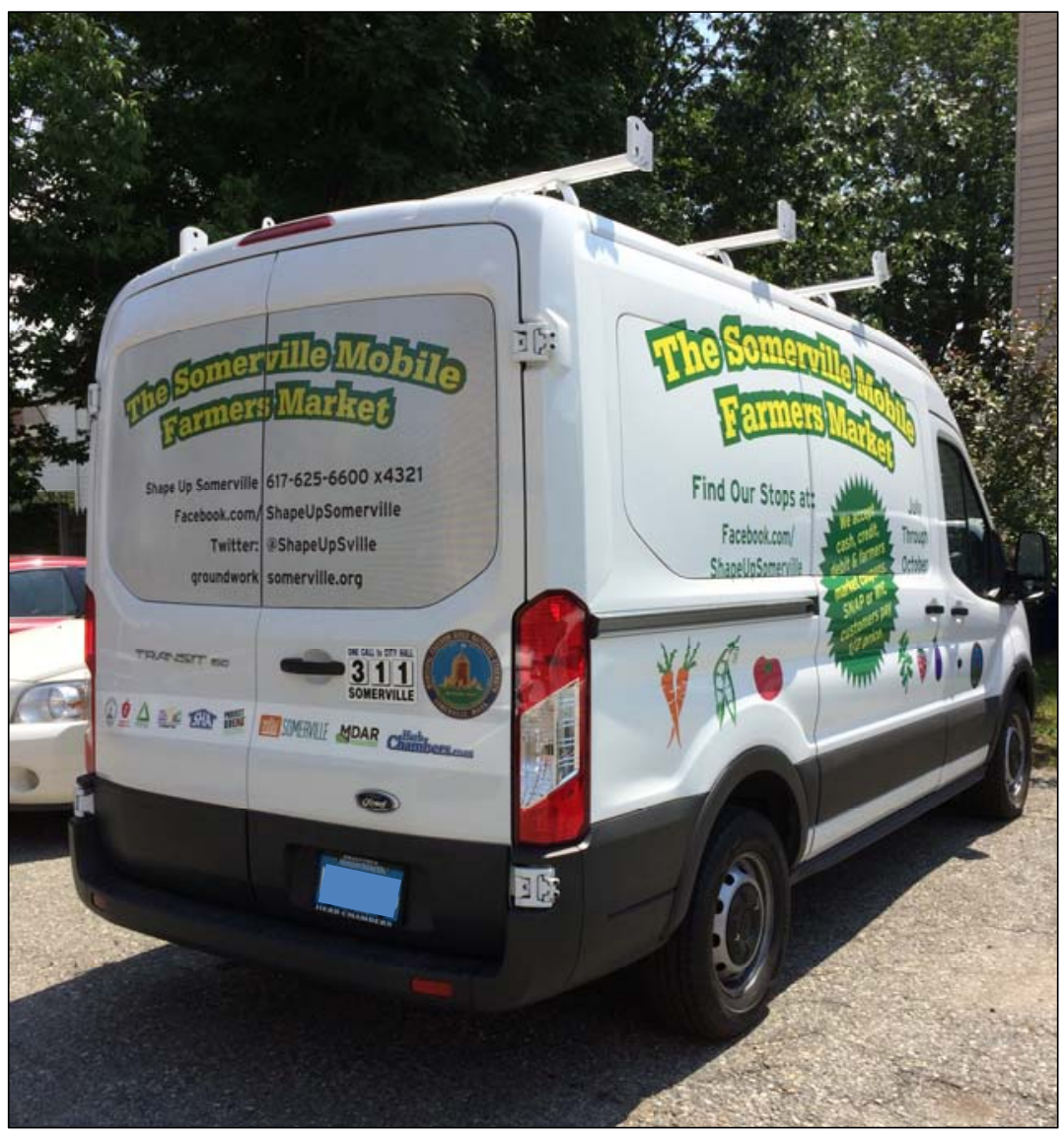

abilities to build policies that increase equity in the local food system.

We also use this valuable feedback and awareness to change our produce offerings. The market has steadily expanded over the years, but the main critique we heard last year was that we do not carry enough fruit and culturally relevant produce. Through consistent program evaluation and attention to customer input, we expanded the market from the original model of working with just one farm to working with four. While logistically difficult, especially as a municipality, this process was necessary to truly meet our customers' needs, which differ from customers of many traditional white upper-class farmers' markets. Farmers' markets continue to grow and contribute to the fabric of their communities but cost, market schedules, and locations often isolate low-income communities, communities of color, and immigrant communities from participating, contributing to the perception of markets as an elite luxury. By diversifying our produce to reflect the preferences of the community, keeping the produce affordable, and making the market mobile, The Somerville Mobile Farmers' Market has contributed to food justice in our community. Changing our stocking practices also helps us limit the paternalistic practice of only providing produce available in our dominant food supply- the produce that mainstream America has determined is healthy rather than valuing diverse community knowledge about healthy foods and stocking the produce the community requests.

Additionally, a common refrain at farmers' markets serving lowincome communities, communities of color, and immigrant populations across the country is that "we have to educate our shoppers about healthy food and how to cook it." On the contrary, 
Figure 2. Rolling racks let us set up in any space and move quickly.

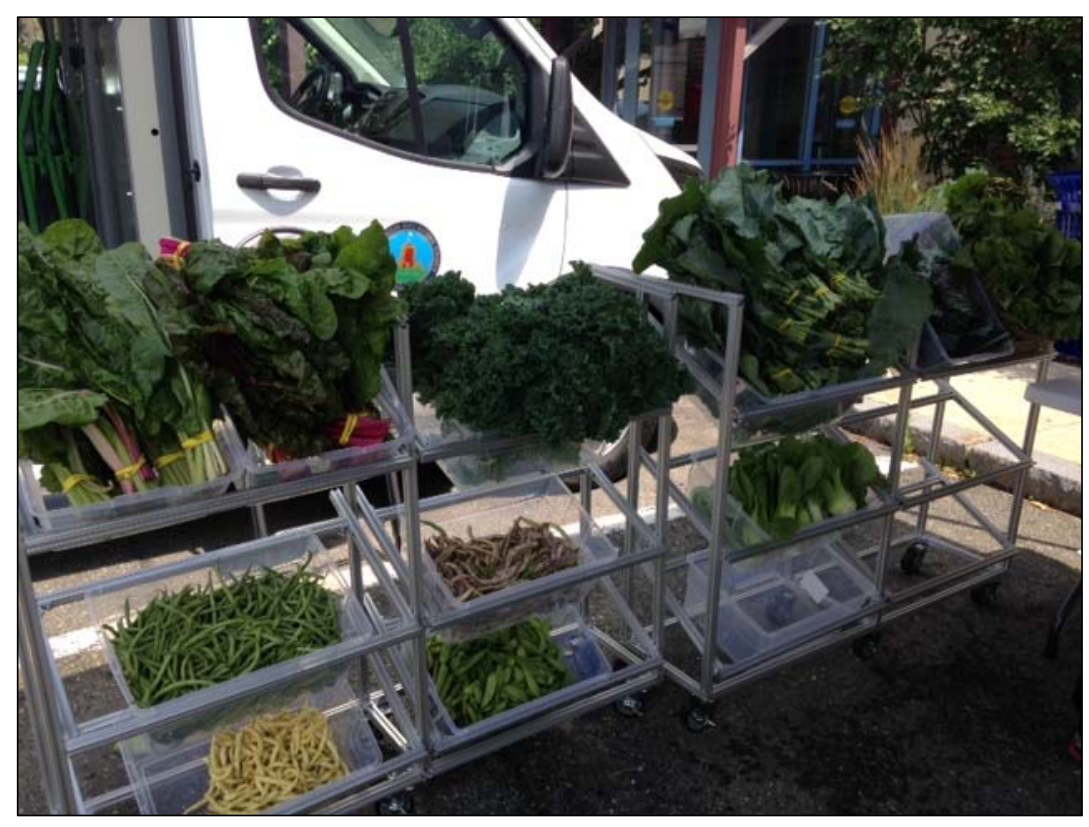

we had based the market on the traditional deficit-model approach, assuming that our customers do not know how to cook or eat healthfully. The reality, rather, is that there are systemic barriers to culturally relevant opportunities for healthful eating that are related to price and supply-chain availability. We are bridging that gap and bringing healthy and culturally appropriate produce to our communities who are asking for it. We who set up the market learn about cultural produce that is new to us alongside our customers learning about other types of produce that are new to them. It is this collaborative learning and valuing of

we at The Somerville Mobile Farmers' Market have found that community members have a wealth of knowledge on cooking healthy food; it's just not always the food with which we white, middle-class, American-born people are familiar. Our customers come together at the market and take part in both structured and organically occurring recipe swaps, sharing everything from Trinidadian callaloo stew recipes to Armenian eggplant techniques and Latin sancocho variations, a process valuing community knowledge and cohesion as well as cultural preservation and celebration. Those of us setting up the market could never have facilitated these values if community knowledge that we aim for in our programming.

The Somerville Mobile Farmers' Market continues to evolve, with our ultimate goal to develop a more sustainable, systemic approach to increasing access to healthy food for all in our city. We are looking into facilitating changes in supply chains to bodegas and corner stores to increase affordability and cultural relevance of their produce year-round and other opportunities. No matter which direction we take, community engagement, a justice lens, and community respect must be the foundation of our work. 